Revista de Estudios Histórico-Jurídicos

[Sección historia del derecho canónico]

XLII (Valparaíso, Chile, 2020)

[pp. 235-259]

\title{
EL HIEROCRATISMO POLÍTICO EN LA PRIMERA LEGISLACIÓN ANTI-HERÉTICA DE INOCENCIO III: EL INTERDICTO A OrVIETO (1198), LA CARTA AL OBISPO DE SiRACUSA (1198) Y LA DECRETAL VERGENTIS IN SENIUM (1199)
}

[The political hierocratism in the first anti-heretical legislation of Pope Innocent III: interdict to Orvieto (1198), Letter to the Bishop of Syracuse (1198) and decretal Vergentis In Senium (1199)]

\author{
Javier BELDA INIESTA* \\ Universidad Católica de Murcia, España
}

\begin{abstract}
RESUMEN
Este artículo pretende mostrar cómo la transición del cesaropapismo otoniano a la aplicación más valiente de las teorías hierocráticas del poder puede ser rastreada analizando no solo desde la perspectiva de las luchas más o menos abiertas entre el papado y el Imperio, sino también desde la perspectiva de la colaboración necesaria en la lucha contra el enemigo común, la herejía, a la que se opusieron de forma conjunta los representantes de los poderes que gobernaban el mundo. El ejemplo paradigmático es el pontificado de Inocencio III, quien, en tres de sus primeras intervenciones normativas contra la herejía (el interdicto a Orvieto del 1198, la carta al obispo de Siracusa del 1198 y la Vergentis in senium del 1199), así como en su apoyo a las Órdenes Religiosas, demostró desde el principio la intención de responder al mundo secular y a la herejía aplicando de forma concreta la teoría hierocrática, ejerciendo así la nueva concepción del poder madurada por sus antecesores.
\end{abstract}

\section{Abstract}

This article aims to show how the transition from Otonian cesaropapism to the bravest application of hierocratic theories of power can be traced by analyzing not only from the perspective of more or less open struggles between the papacy and the Empire, but also from the perspective of the necessary collaboration. In the fight against the heresy, which was jointly opposed by the representatives of the powers that ruled the world. The paradigmatic example is the pontificate of Innocent III, who, in three of his first normative interventions against heresy (the injunction to Orvieto of 1198 , the letter to the Bishop of Syracuse of 1198 and the Vergentis in senium of 1199), and with his support for the Religious Orders, demonstrated from the beginning the intention of responding to the secular world and heresy by applying in a concrete way the hyerocratic theory, thus exercising the new conception of power matured by its predecessors.

*Profesor Ordinario de Historia del Derecho y de las Fuentes Canónicas; e-mail: jbelda@ ucam.edu 
Palabras Clave

Hierocratismo - Inocencio III - Vergentis in Senium - interdicto - carta al obispo de Siracusa - herejía.
Key Words

Hierocratism - Innocent III - Vergentis in Senium - Interdict - Letter to the Bishop of Syracuse - Heresy.

RECIBIDO el 24 de marzo de 2020 y ACEPTADO el 4 de mayo de 2020

\section{INTRODUCCIÓN}

Pese a los múltiples intentos por parte del papado y los poderes civiles por atajar el problema de la herejía en la Edad Media con continuas reformas, que arrancaban ya desde antiguo y que abarcaban todas las vertientes en las que la Iglesia ejercía su acción, pocos fueron los frutos obtenidos. De hecho, las medidas aplicadas en los siglos posteriores a la reforma gregoriana, acaso por poco articuladas, no dieron el fruto deseado, sino más bien el contrario: tras los grandes concilios ecuménicos de la época antigua, la mayor crisis herética de la Iglesia se planteó en los siglos XII y XIII.

La lucha contra este enemigo suponía, además, una prueba de fuego de la autocomprensión de la Iglesia y del propio papado, conceptos esenciales en el momento. Por un lado, al enfrentarse ésta a un enemigo nacido en su interior y al hacer un esfuerzo por erradicarlo, adquiere una mayor conciencia del depósito de fe que le ha sido encomendado, así como la capacidad de organizarse de la mejor manera posible para llevar a cabo la tarea de salvaguardar el mensaje de salvación de forma integral, y de oponerse a cualquier intento de corrupción. A su vez, el pontífice, con ocasión de la lucha contra la herejía, indaga sobre el alcance y los límites de su prestigio y de la autoridad que posee. De hecho, la evolución de las relaciones con el emperador, un aliado necesario en la lucha contra la heterodoxia, surge de las medidas normativas antiheréticas, en las que se asiste al paso repentino de la cooperatio paritaria entre regnum y sacerdotium a una concepción de vasallaje de la potestad civil con respecto a la autoridad espiritual más extensa. Misma que incluyó en sí misma todos los poderes que se ejercen en el mundo, por voluntad divina expresa.

De este modo, la transición del cesaropapismo otoniano, heredado y llevado a sus consecuencias más extremas por Barbarroja, a la aplicación más valiente de las teorías hierocráticas del poder, nacidas en el seno de las escuelas de derecho de la Baja Edad Media, se pone de manifiesto analizando con atención las decisiones políticas adoptadas por los pontífices en la lucha contra la herejía ${ }^{1}$. Por lo tanto, el punto de inflexión hierocrático en la concepción y administración de los poderes supremos de la sociedad medieval puede observarse no solo desde la perspectiva de las luchas más o menos abiertas entre el papado y el Imperio, sino también desde la perspectiva de la colaboración necesaria en la lucha contra el enemigo común, la herejía, a la que se opusieron de forma conjunta los representantes de los poderes que gobernaban el mundo ${ }^{2}$.

${ }^{1}$ Nichols, Terence, Hierarchy and the Church, en Pro Ecclesia, 4/3 (1995), pp. 281-300.

${ }^{2}$ Haldén, Peter, Heteronymous Politics beyond Anarchy and Hierarchy: The Multiplication 
Así, el cambio de ritmo en la administración del poder, preparado por sus predecesores durante largos siglos de historia, está marcado por el pontificado de Inocencio III, de 1198 a 1216. El papa-Lotario dei Conti di Segni en el siglo- pese a que accedió al trono petrino con solo treinta y siete años de edad, demostró desde el principio la intención de responder al mundo secular y a la herejía aplicando la nueva concepción del poder madurada por sus antecesores. De hecho, como veremos, en una de sus primeras actividades normativas, la decretal Vergentis in senium (1198), promulgada al comienzo de su pontificado, se observa claramente la intención de aplicar de forma concreta la teoría hierocrática. La energía y determinación del joven pontífice, teólogo y jurista, llevaron a la aplicación más sistemática y proficua de su visión del poder en la Baja Edad Media ${ }^{3}$.

Pero la estructuración judicial de la persecución no fue el único instrumento que utilizó Inocencio III para luchar contra la herejía, pues pretendía una renovación global de la realidad eclesial, propósito que alcanzaría su culmen en la convocatoria del IV Concilio Lateranense. Junto a la aplicación de la teoría hierocrática, Inocencio potenció la reforma de las órdenes religiosas y la aprobación vivae vocis oraculo del Propositum de Francisco de Asís, orientadas a estimular la predicación de la Buena Nueva, contrarrestar la difusión de las herejías y acoger en la Iglesia los movimientos pauperistas y de regeneración del espíritu de imitación de Cristo. La elección de los sucesores de Inocencio III de enviar a los religiosos como inquisitores por toda Europa responde a la decisión de encomendar la lucha contra la heterodoxia a personas preparadas y fieles al pontífice, al que debían rendir cuentas de su labor, y enviadas para llenar los vacíos de la inquisición episcopal, que no había sabido frenar de forma eficaz la difusión de la doctrina cátara. De ahí nace la gran fortuna de las órdenes mendicantes nacidas entre los siglos XII y XIII, que predicaban el retorno a la pobreza de la Iglesia de los orígenes y que, al menos en un principio, establecían que el voto de pobreza no debía ser solo individual, sino también colectivo, en el sentido de que todo el convento debía vivir de los frutos de la colecta.

\section{INOCENCIO III, LA HEREJÍ́ Y LAS ÓRDENES RELIGIOSAS}

El carácter decidido del nuevo sucesor de Pedro surgió desde el inicio de su pontificado, cuando hizo propio el proyecto de reivindicación del P a t r i m o $\mathrm{n}$ i o d e P e d r o por parte de la Santa Sede, ya iniciado por su predecesor, Clemente

of Forms of Rule 750-1300, en Journal of International Political Theory, 13/3 (2017), pp. 266281; BIRD, Jessalynn, Innocent III, Peter the Chanter's Circle, and the Crusade Indulgence: Theory, Implementation, and Aftermath, en SOMMERLECHNER, Andrea (ed.) Innocenzo III: Urbs et Orbis, Atti del Congresso Internazionale (Roma, 9-15 settembre 1998) (Rome, 2002), I, pp. 503-524.

${ }^{3}$ MESCHINI, Marco L'evoluzione della normativa antiereticale di Innocenzo III dalla «Vergentis in senium» (1199) al IV concilio lateranense (1215), en Bullettino dell'Istituto Storico Italiano per il Medio Evo, 106/2 (2004), pp. 207-231; ÉL MISMO, Validità, novità e carattere della decretale "Vergentis in senium» di Innocenzo III (25 marzo 1199), en Bulletin of the Medieval Canon Law, 25 (2002-2003), pp. 94-113. 
III ${ }^{4}$. En este sentido, hábil lector de los acontecimientos que lo rodeaban, planteó, desde el comienzo de su pontificado, la utilización de todos los medios a su alcance para llevar a cabo su pretendida tarea de renovación.

Uno de los primeros medios se encontraba, además, en un espacio en el que era incontestable su autoridad: dentro de la misma Iglesia. Desde el principio entendió que la vida consagrada, que hasta entonces habían sido vehículo mediante el cual el Espíritu había animado y sostenido el caminar de la Iglesia, con el paso del tiempo se habían convertido en lastre que ya no ayudaba a afrontar las nuevas circunstancias. A sus ojos, la vida monástica, que ayer fue tronco que, brillante de ascua, llenaba de calor a la Iglesia, hoy parecía más bien ceniza consumida por las llamas, y lo que había servido para vigorizar el hogar ahora ahogaba los pocos rescoldos que luchaban por continuar prendidos. Así, las órdenes religiosas, que durante el final de la época antigua y gran parte de la Edad Media habían sido el motor principal que sirvió para mantener viva la fe y la ortodoxia en una Europa que a duras penas era capaz de entenderse a sí misma yendo de un Imperio a otro, en los últimos siglos de la era medieval debía reinventarse para adecuarse a un mundo que, revestido de ciudades, cambiaba señores por reyes para, a lo lejos, empezar a soñar los estados 5 .

Fueron los pontífices de los dos momentos claves, esto es, su nacimiento y su evolución a las órdenes mendicantes, quienes mejor supieron leer los tiempos para, preservando los carismas, utilizaros para fortalecer la Iglesia. Del mismo modo que Gregorio Magno había utilizado la regla benedictina para afrontar la expansión evangelizadora en tierras donde la estructura imperial apenas existía ${ }^{6}$, Inocencio se apoyó en los nuevos movimientos de su época para su lucha contra

${ }^{4}$ Escribe a este respecto Michele Maccarrone: "Innocenzo III manifestò subito all'inizio del proprio pontificato la volontà di condurre un'azione politica che restituisse alla Sede apostolica quelli che rivendicava essere suoi territori, ad essa soggetti temporalmente. Egli era conscio dei rischi che ciò importava, ed in primo luogo dovette superare un problema di coscienza, vivo nel suo animo sinceramente religioso, costituito dal fatto che l'azione politica da lui condotta impegnava sé come papa, e la Chiesa romana, nelle implicazioni di una politica angusta e deteriore, abbassandosi al grado ed ai metodi di un signore locale della provincia italiana; e d'altra parte era privo di una vera forza militare e di una struttura politica, che dessero stabilità e frutti duraturi ai suoi continui e logoranti interventi personali” (MACCARRONE, Michele, Studi su Innocenzo III (Padua, 1972), p. 10. El biógrafo anónimo de Inocencio, su coetáneo y cercano al pontífice, relata su preocupación por esta política de $\mathrm{r}$ e f o $\mathrm{r} \mathrm{m}$ a del patrimonio de la Iglesia, y cuenta que, a menudo, el pontífice demuestra su perplejidad pronunciando la frase del Sirácida "Qui tangit picem, coinquinabitur ab ea" (Sir. 13, 1: "El que toca el alquitrán se ensucia los dedos”), Gesta Innocentii Pp. III ab auctore anonymo, sed coetáneo, scripta, n. XVII, en PL., 214, pp. XXIX-XXX.

${ }^{5}$ CARdini Franco, Crociata e religione civica nell'Italia medievale. In "La religion civique à l'époque médiévale et moderne (chrétienté et islam), en Actes du colloque organisé par le Centre de recherche "Histoire sociale et culturelle de l'Occident. XIIe-XVIIIe siècle» de l'Université de Paris X-Nanterre et l'Institut universitaire de France (Nanterre, 21-23 juin 1993) (Rome, 1995), pp. 155-164; Heller, Sarah-Grace, Anxiety, Hierarchy, and Appearance in Thirteenth-Century Sumptuary Laws and the Roman de la rose, en French Historical Studies 27/2 (2004), pp. 311-348.

${ }^{6}$ BELDA INIESTA, Javier, Civitate evangelii vs evangelium in civitate: el binomio evangelio-mundo en la evolución de la vida consagrada medieval, en Commentarium pro Religiosis et Missionariis, 97/1-2 (2015), p. 79. 
la herejía, entendiendo que las nuevas formas de consagración que estaban surgiendo como consecuencia de la confluencia de la vida urbana y de la crisis de la vida monástica hacían necesaria una regulación explícita. Maccarrone ha puesto ya de manifiesto que Inocencio III no se limitó a simplemente confirmar a los nuevos movimientos, sino que se sirvió de ellos para llevar a cabo su reforma ${ }^{7}$. De hecho, si bien el canon 13 del IV Concilio del Letrán se ha considerado a veces más una cortapisa a tales movimientos que una ayuda a los mismos -sobre todo en relación a la aprobación oral de la regla franciscana ${ }^{8}$-, en realidad supuso un fortalecimiento a las posibilidades de difusión de las fundaciones, eso sí, sin multiplicar las reglas?.

Las estructuras existentes, alejadas de las ciudades o excesivamente burocratizadas en las diócesis, y carentes del mínimo prestigio espiritual -por no hablar de su escasa preparación teológica-, no eran capaces ni tan siquiera de acercarse a un pueblo del que vivían completamente alejados. Era pues, necesaria, una realidad nueva, formada por teólogos y que encarnase los auténticos valores del evangelio, que pudiera hacer frente a la amenaza, y que, cuando algún movimiento cruzase la línea roja y pasara de renovador a hereje, tuviera capacidad de ofrecer una respuesta adecuada con su mismo lenguaje.

Con esta intención, se recurrió en un primer momento a la orden del Cister ${ }^{10}$ ya que, por su santidad y rigor, podían sin ningún problema enorgullecer a la Iglesia como hijos fieles frente a los perfecti cátaros. Sin embargo, su falta de preparación y su misticismo hizo que no dieran el resultado esperado.

Ante el fracaso de los cistercienses, el papa volvió sus ojos hacia esos nuevos grupos que pretendían vivir la pobreza de Cristo bajo su amparo, y que le habían sugerido que el modo más idóneo de enfrentarse a la aureola de espiritualidad cátara consistía utilizar sus mismas armas y realizar una prédica inteligible por las personas menos cultas, utilizando su mismo lenguaje. Se trataba de volver a llevar el Evangelio a las ciudades, sacándolo de las ciudadelas en las que se había refugiado

${ }^{7}$ Maccarrone, Michele, Studi su Innocenzo III, cit. (n. 4), p. 197: "Este esquema sobre la aprobación de nuevas instituciones religiosas, dado por Inocencio III antes del Concilio Lateranense IV, clarifica su pensamiento e indica una línea definida de conducta. Inocencio III intervino frecuentemente, marcando un desarrollo opuesto a los papas precedentes, con la intención de reservar tales cuestiones a la Sede Apostólica, y, después de la experiencia de los Humillados, se sirvió de la distinción entre religiones regulares y comunidades o grupos de fieles y de clérigos, asimilados a los penitentes, o bien a los predicadores diocesanos bajo el cuidado inmediato de los obispos. La aprobación que él les daba tenía la finalidad de alentar su propositum y de recomendarlos a los obispos, con miras, principalmente, a la predicación contra la herejía, sin dar a tal aprobación el carácter de una confirmación como verdaderos institutos religiosos; cuando había una solicitud de semejante confirmación, el papa encaminaba la nueva fundación hacia las reglas e instituciones ya existentes".

${ }^{8}$ No entraremos aquí a discutir si en realidad el objetivo era no sentar precedente o adecuarse a las necesidades, ni a todo lo referente a la posterior aprobación formal de los franciscanos. Powell, James, El papado y los primeros franciscanos, en Selecciones de Franciscanismo, 8/23 (1979), pp. 265-276.

${ }^{9}$ Maccarrone, Michele, Studi su Innocenzo III, cit. (n. 4), p. 304.

${ }^{10}$ Belda InIESTA, Javier, La respuesta de la Iglesia a la herejía medieval. Aproximación históricojurídica (Città del Vaticano, 2014), p. 203. 
para huir de un mundo que ya había llegado a ellas o que, como hemos visto, estaba demasiado alejado de las mismas ${ }^{11}$. Había pues, que luchar en el mundo con las armas del mundo, y para esto eran más adecuadas las nuevas realidades que parecía sugerir el Espíritu. Atendiendo a esta indicación el papa el 17 de noviembre de 1206 ordenó buscar y convertir a los herejes, imitando la pobreza y humildad de Cristo ${ }^{12}$. Surgió así la primera orden mendicante, los dominicos; y, muy poco después, en 1210, autorizaría verbalmente a Francisco de Asís la fundación de otra orden de predicadores. En este punto, la relación entre el franciscanismo y el papado ha sido objeto de numerosas discusiones pues, habitualmente, los estudios se han centrado más en la persona de Francisco y en la persecución de sus ideales que en su función al servicio del pontífice, lo que ha desembocado en la dicotomía entre el reformador místico y el servidor del papado ${ }^{13}$.

Independientemente de las circunstancias que rodearán a su nacimiento, o a los problemas que aparentemente se pondrán a las nuevas formas de consagración, lo que está claro es que fueron franciscanos y dominicos los que abordaron la empresa de llevar a la gente el mensaje ortodoxo de la Iglesia y detectar las desviaciones que se estaban produciendo ${ }^{14}$. De hecho, el interés de la predicación bajomedieval reside precisamente en su determinación por llevar el Evangelio a los laicos y gentes iletradas, lo cual exigió una adaptación del mensaje y del procedimiento oratorio a los nuevos oyentes. Un recurso nada novedoso, pero no por ello menos efectivo, será el exeplum ${ }^{15}$, que tenía por objeto ejemplificar y hacer cobrar vida a las palabras. Era, ante todo, discurso oral, que acompañado por la voz y vivificada por los gestos se transformaba en palabra viva y que permitía fabricar un discurso ágil y fresco, que mantuviera el interés del oyente durante más tiempo, consiguiendo así erradicar un enemigo que desapercibido era me-

${ }^{11}$ BeLda InIESTa, Javier, Civitas evangelium vs evangelium in civitate, cit. (n. 6), passim.

${ }^{12}$ RankIn, Travis, Jurisdiction in the Sacrament of Penance: A Canonical- Theological Schema (Leuven, 2011), p. 12.

${ }^{13}$ Powell, James, El papado y los primeros franciscanos, cit. (n. 8), p. 265.

${ }^{14}$ Belda Iniesta, Javier, La respuesta de la Iglesia contra la herejía, cit. (n. 6), p. 213. No pretendemos entrar en la discusión clásica de Sabatier sobre si era o no intención de San Francisco fundar una orden, y nos limitamos a constatar el hecho de que, de modo organizado, y con aprobación pontificia, comenzaron a trabajar en la nueva evangelización [Vid. SABATIER, Paul, Vita di san Francesco d'Assisi (Milán 1978)].

${ }^{15}$ Bravo, Federico, Arte de enseñar, arte de contar. En torno al "exemplum" medieval, en De La Iglesia Duarte, José Ignacio (a cura di), La enseñanza en la edad media: X Semana de Estudios Medievales (Nájera, 1999), pp. 303-328 y visible en internet: http://www.vallenajerilla. com/berceo/bravo/exemplum.htm (consultado 11.07.2019): "modalidad del discurso didáctico cuya característica más notable es, precisamente, la de hacer coincidir en uno solo dos artes diferentes: el arte de enseñar y el arte de contar. A él recurren a lo largo de la Edad Media, y de forma especialmente masiva a partir del siglo XIII, profesores, oradores, moralistas, místicos y predicadores, para ejemplificar y adornar sus exposiciones ilustrándolas mediante todo tipo de fábulas, anécdotas, cuentecillos, bestiarios, relatos históricos, apólogos, historietas, leyendas, etc. De origen sagrado o profano, tomado de fuentes orientales u occidentales, improvisado por el autor o sacado de la tradición popular, de la antigüedad clásica o medieval, el fondo narrativo de que se nutre el discurso didáctico medieval es propiamente ilimitado. Ficción narrativa concebida para servir de demostración, el ejemplo es pues, a un tiempo, un método didáctico y un género literario". 
nos preocupante: el tedio. Evidentemente, el objetivo era atraer la atención del público y comunicar un mensaje moral ${ }^{16}$. Debemos recordar que esta técnica no es en absoluto novedosa, pues ya fue raíz de la trasmisión del evangelio desde los primeros pasos de éste: "Vobis datum est nosse mysteria regni Dei, ceteris autem in paraboli"17, consiguiendo así exponer los dogmas de fe más complejos, o los que podían haber puesto en duda los herejes, con algo reconocible y ordinario. Esto, unido al testimonio de vida de quienes los transmitían, fue el elemento definitivo que devolvió el Evangelio a las ciudades.

Inicialmente, la tarea de estas órdenes no puede considerarse propia de una organización estable, ni revestía el posterior carácter inquisitorial. Pero fue precisamente la tarea que desarrollaron la que puso de manifiesto la necesidad de establecer una institución de carácter supranacional, que tuviese la suficiente fuerza y autonomía para obrar en toda Europa, con independencia orgánica de cualquier otra autoridad eclesiástica, exceptuando, claro está, la del papa ${ }^{18}$.

Este aspecto será fundamental, ya que permitirá fortalecer uno de los puntos basilares sobre los que descansaba la Iglesia en aquella época y que más ataques, internos y externos, recibía: la fortaleza del papado. Los grandes monasterios, muchos de ellos en franca decadencia, no siempre se habían mostrado fieles al papado, pues algunos seguían incluso en manos laicas. Estas nuevas órdenes, sin embargo, más flexibles en sus movimientos, y ardientes del celo propio de los recién fundados, dependían directamente del papa, lo que, en principio, debía garantizar su fidelidad. Además, como ya hemos dicho, la vida comenzaba a concentrarse en las ciudades, lo que reducía la dependencia de la población del monasterio, tanto espiritual como económica, y dificultaba que los monjes atendieran pastoralmente a los fieles.

Así, consciente de la trascendencia que tenían los nuevos movimientos religiosos, el papa prestará especial atención a su regulación pues, si bien habían nacido como contrapunto a las desviaciones que vivían los movimientos clásicos, por su propia naturaleza correrán el riesgo de caer en la negación de la estructura en lugar de en su reforma. Aún era demasiado reciente el caso de Joaquín de Fiore cuya labor, en un primer momento, no sólo fue permitida, sino patrocinada, lo que pone de manifiesto que la conciencia romana de la existencia de determinados problemas, a la vez que la necesidad de controlar las respuestas espontaneas que pudieran surgir.

En este sentido, una de las líneas principales que delimitaron la política pontificia durante este periodo fue el intento de unificación de las órdenes religiosas,

${ }^{16}$ Los especialistas del tema distinguen entre dos tipos de relatos morales: el exemplum o breve narración de un acontecimiento pasado ejemplarizante y la similitudo o comparación con la vida cotidiana que reporta una enseñanza (BRÉMOnd, Charles; LE Goff, Jacques; SCHMITT Jean Claude, L'Exemplum² (Turnhout, 1996), pp. 154-156.

${ }^{17} \mathrm{Mt} \mathrm{8,} 10$.

${ }^{18}$ Como ya hemos dicho, uno de los mayores problemas con los que se enfrentaron los dominicos y franciscanos, así como el clero secular para encontrar a los herejes, consistió en el hecho de que la ortodoxia cristiana todavía no estaba bien definida, y, por lo tanto, hasta a los teólogos más preparados les resultaba difícil identificar cuáles eran las posiciones heterodoxas. 
organizadas bajo muy diversas reglas. El objetivo era claro: si se conseguía dar un perfil uniforme a la vida consagrada, controlando la base sobre las que se asentaría la vida cotidiana de los religiosos, se podría conseguir que fueran éstos los que influyeran en el mundo y no el mundo en ellos, riesgo que como hemos visto siempre acompañó a la vida monástica ${ }^{19}$.

$\mathrm{Al}$ mismo tiempo, la nueva configuración de la vida social, que abandonaba los campos y comenzaba a poblar las ciudades, favorecía el surgimiento de nuevos movimientos lo que, junto a las carencias de la vida eclesial que ya hemos puesto de manifiesto, aumentaba exponencialmente el riesgo de contagio. En este sentido, el éxito de los grupos penitenciales en el sur de Francia, que había adquirido una experiencia considerable trabajando entre los grupos heréticos del lugar.

Algunos han puesto de manifiesto que no fue una actitud surgida de la nada, en lo que a las pretensiones legislativas se refiere, pero no cabe duda de que, pese a seguir una línea marcada anteriormente "ma rimane la sua originalità, che debe essere inquadrata nell'azione di Innocenzo III di reforma e unificazione della vita religiosa" 20 .

Sin embargo, en un primer momento el papa optó por continuar las prácticas curiales: en la aprobación de los hospitalarios del Espíritu Santo ${ }^{21}$ la fórmula empleada no habla de regla: "statuentes ut frates inibi commorantes secundum rationabiles intitutiones tuas perpetuo Domino debeant famulari" 22 . Esta fórmula, ya empleada por Celestino III dos años antes para aprobar la separación de Joaquín de Fiore de los Cistercienses: "Nos igitur tuis precibus inclinati, praedictas constitutiones, sicut a te provide factae sunt, auctoritate apostolica confirmamu" 23 .

El primer intento de unificación se produjo en Livonia en 1201, donde se invitó a los religiosos a unificarse bajo la misma regla ${ }^{24}$. Pese al fracaso de este intento,

${ }^{19}$ Powell, James, El papado y los primeros franciscanos, cit. (n. 8), p. 266.

${ }^{20}$ Maccarrone, Michele, Studi su Innocenzo III, cit. (n. 4), p. 263.

${ }^{21}$ El 23 de abril de 1198. Esta orden, nacida en Montpellier hacia 1174, fue aprobada por el papa Inocencio III mediante la bula "His Pricipue" del 22 de abril de 1198 y confirmada solemnemente por el mismo pontífice en la Bula "Religiosam Vita" del 25 de noviembre del mismo año. Maccarrone ha rastreado su procedencia en el "Bullarium Sancti Spiritus", manuscrito del XVIII conservado en la Biblioteca Lancisiana del Hospital del Espíritu Santo de Roma, que a su vez se corresponde con otra copia encontrada en el Archivio di Stato di Roma. Esta será más solemne que la de abril, pues a la firma pontificia se añaden las de los cardenales.

${ }^{22}$ InNOCENTIUs III, Epistola 97 Guidoni fundatori Hospitalis Sancti Spirtus, en PL., 214, col. 85-86.

${ }^{23}$ Caelestinus III, Epistola 279 Joachini abbatis, en PL., 206, col. 1183. Para la discusión sobre el continuismo o la ruptura de la política pontificia en relación a los nuevos movimientos, vid. las obras de Powell o de Maccarrone citadas.

${ }^{24}$ Ciertamente, esta orientación seguía los cauces previamente marcados por Clemente III (abril de 1190) y la posterior confirmación por parte de Celestino III (tres años después), en la que se autorizaba al obispo del lugar a dispensar de sus propias reglas y se le concedía otra serie de prebendas (para más información, cfr. VICAIRE, Marie-Humbert, Vie commune et apostolat missionnaire. Innocent III et la mission de Livonie, en Dominique et ses Prêcheurs, (Fribourg, 1977), pp. 180-197; MacCarrone, Michele, I papi e gli inizi della cristianizzazione della Livonia, en ÉL MISMO, Gli inizi del Cristianesimo in Livonia-Lettonia. Atti del Colloquio internazionale di storia ecclesiastica in occasione dell'8 centenario della chiesa in Livonia (1186-1986) (Città del 
habrá una nueva prueba, esta vez con la vida religiosa femenina, con el proyecto de universale coenobium ${ }^{25}$, en el que Inocencio III perseguirá celosamente construir un gran monasterio que albergase a todas las religiosas de Roma en San Sixto ${ }^{26}$.

\section{El Interdicto a OrVieto}

Al tiempo que afrontaba una reforma interna, Inocencio dirigió también sus esfuerzos a lo externo, actuando con dureza contra los focos heréticos cuyas brasas seguían tan vivas como cercanas. De hecho, cuando llevaba poco tiempo en el trono petrino (8 de enero de 1198), Inocencio III castigó a la ciudad de Orvieto con el interdicto y convocó en Roma al obispo de la ciudad, que durante nueve meses permaneció como huésped del pontífice ${ }^{27}$. No era la primera ni la última medida drástica tomada por Inocencio para recuperar el gobierno temporal de la Iglesia en el centro de Italia: en este caso, el interdicto fue la "formalización de máxima culpabilidad colectiva" 28 .

Las dos medidas debieron parecer muy severas, puesto que estaban destinadas a resolver una cuestión estrictamente temporal, como el control político de una fortaleza, que ya era objeto de disputa desde hacía tiempo: el interdicto afectaba a la vida espiritual del pueblo de Orvieto. La segunda medida, en determinados aspectos, era también grave, puesto que la llamada del obispo a Roma sonaba como una admonición para la Comuna. Con esta decisión, de hecho, Inocencio III advertía de que, si Orvieto hubiera persistido en su obstinada oposición al pontífice, este la habría privado definitivamente de la sede episcopal. De esta forma, le habría quitado a Orvieto su propia identidad de ciudad, que derivaba precisamente de la presencia de la sede episcopal dentro de sus muros; mientras que el clero ciudadano habría estado sometido al obispo de una diócesis cercana ${ }^{29}$.

En virtud del interdicto que afectaba a Orvieto, los oficios sagrados no podían ser ejercidos; se habían suspendido las celebraciones eucarísticas, la catequesis, la liturgia de las horas; las Iglesias debían permanecer cerradas, celebrándose los sacramentos en secreto ${ }^{30}$. La censura debía inducir a la ciudad a reconocer a la

Vaticano, 1989), pp. 31-80; BourgeOIs, Nicolas, Les Cisterciens et la croisade de Livonie, en Revue historique, 635/3 (2005), p. 523.

${ }^{25}$ Maccarrone, Michele, Studi su Innocenzo III, cit. (n. 4), p. 272.

26 "Sed dum promotioni dicti loci ferventissimo insistert animo, norte preventus, monasterium imperfectum reliquit".

${ }^{27}$ Maccarrone, Michele, Studi su Innocenzo III, cit. (n. 4), pp. 27-28. El obispo Ricardo se alejó de Orvieto contra su voluntad: es lo que se desprende de la Passio S. Petri Parenti Martyris ("novem fere mensibus invitum Romae detinendo Episcopum in suae opprobrium Civitatis", Passio S. Petri Parenti Martyris, en CARTARI, Stefano (a cura di), Istoria antica latina, e sua traduzione in lingua italiana del Martirio di S. Pietro di Parenzo, Orvieto, 1662, p. 7).

28 "Pontifex Urbetanos anathematis vincula innodavit", ibíd.; cfr. CLARKE, Peter, The Interdict in the Thirteenth Century (Oxford, 2007) especialmente el capítulo primero, dedicado a la justificación del interdicto en el pensamiento medieval, pp. 14 y ss.

${ }^{29}$ Maccarrone, Michele, Studi su Innocenzo III, cit. (n. 4), p. 28.

${ }^{30}$ KREHBIEL, Edward, The Interdict: its history and its operations (Washington, 1909), pp. $15-74$. 
Santa Sede el gobierno de la fortaleza de Acquapendente, que ocupaba una posición estratégica en las posesiones pontificias: de esta forma el pontífice ejercía su presión sobre los habitantes y los gobernantes de Orvieto ${ }^{31}$.

Las intervenciones de Inocencio, sin embargo, tuvieron efectos opuestos a los esperados: fomentaron sentimientos de desprecio y rencor hacia la jerarquía eclesiástica, debilitando aún más el ya frágil vínculo que unía al pueblo de la ciudad con el clero. El conflicto que, desde 1150, había visto medirse a los obispos del lugar, las familias aristocráticas y las instituciones comunales, no había jugado a favor de las instituciones eclesiásticas ${ }^{32}$ y el alejamiento del obispo Ricardo de Orvieto representó una oportunidad inédita para los enemigos de la jerarquía. El propio obispo, hasta el momento de su partida hacia Roma, había participado activamente en una lucha global contra la herejía, que había llevado a numerosas condenas a muerte (decapitaciones, ahorcamientos, hogueras, exilios): "ex adverso ascendens, et se murum opponens pro Christi ecclesia defendenda, in tantum est haereticos perfectus, ut alii poenam suspendii sustinerent, alii capite punirentur, alii traderentur flammis [...] alii maiorem capitis maiorem diminutionem perpessi extra Civitatem poenam perpetui exilii deplorarent [...]"33.

El vacío que había dejado la máxima autoridad espiritual en la Comuna fue pronto colmado por los predicadores cátaros procedentes de los centros urbanos cercanos, como Viterbo y otras ciudades ubicadas en el Patrimonio de San Pedro. La dura política de Inocencio III con respecto a la Comuna facilitó el trabajo de los líderes de la comunidad cátara, que iniciaron una campaña de difusión de las doctrinas anticlericales sin precedentes en esa zona geográfica ${ }^{34}$. La predicación herética ganó en poco tiempo la aprobación no solo de una parte considerable del pueblo, sino también de algunos nobles. Los herejes predicaban públicamente e incluso llegaron a amenazar a los católicos con que, una vez convertidos en señores de la ciudad, les habrían confiscado todos sus bienes y les condenarían al exilio, invirtiendo, de hecho, las dinámicas religiosas ciudadanas ${ }^{35}$. Probablemente, tal

${ }^{31}$ A pesar de todo, el papa continuó la producción de textos contra la herejía, como la decretal Cum unus Dominus de 21 de mayo 1198 (Innocentius III, Epistola 94 Aquen. Episcopo et suffraganeis eius, en PL 204, pp. 81-83); Pennington, Kenneth, Innocent III and the Divine Authority of the Pope, Published in Popes, Canonists, and Texts 1150-1550 (Aldershot, 1993); STEVens, Travis Allen, Innocent III et la rhétorique contre l'hérésie, en BrenON, Anne (ed.), 1209-2009: Cathares: Une histoire à pacifier? (Portet-sur-Garonne, 2010), pp. 53-64; KIENZLE, Beverly Mayne, Innocent III's papacy and the crusade years, 1198-1229: Arnaud Amaury, Gui of Vaux-de-Cernay, Foulque of Toulouse, en Heresis, 29 (1999), pp. 49-81.

${ }^{32}$ Lambert, Malcolm, The Cathars, Oxford, 1998, p. 95; Lansing, Carol, Power \& purity: Cathar Heresy in Medieval Italy (Oxford, 1998), pp. 25-41; Loos, Milan, Dualist Heresy in the Middle Ages (Praga, 1974), p. 279. Para Thompson el c a t a r i s m o reunía todas las características para difundirse en las comunas del norte de Italia, indicador de que los grupos clasificados como los herejes se insertaron perfectamente en las elites locales. Cfr. THOMPSON, Augustine, Cities of God: The Religion of the Italian Communes, 1125-1325 (Pennsylvania, 2005), p. $17 \$ 3$.

${ }^{33}$ Passio Sancti Petri Parenti, cit. (n. 27), pp. 6-7.

${ }^{34}$ Maccarrone, Michele, Studi su Innocenzo III, cit. (n. 4), p. 28.

${ }^{35}$ Ibíd., p. 31; conocemos la dificultad de la situación por la Passio Sancti Petri Parenti cit. (n. 27), p. 7: "Ac ita prava doctrina in auditorium mentibus germinavit, ut in tantum haereticorum 
fue la rapidez con la que se difundieron las doctrinas heréticas subversivas que las instituciones de la Comuna se apresuraron a buscar un acuerdo con el papa que permitiera el regreso del obispo a Orvieto y la reanudación de las actividades de represión de la herejía ${ }^{36}$. Este contemplaba, entre otras cosas, el reconocimiento del dominio feudal de la Santa Sede sobre Acquapendente, mientras que Orvieto, ubicada también en el territorio del Patrimonio de Pedro, recibiría del pontífice un rector romano y fiel al papa. La elección de Inocencio III recayó en el romano Pietro Parenzo, que, en febrero de 1199, recibió del pontífice el encargo de restaurar el orden público en Orvieto y, sobre todo, de reanudar decididamente la lucha contra la herejía, facilitando la reconstrucción de la autoridad episcopal ${ }^{37}$. Sin embargo, las esperanzas del pontífice no se cumplieron: en mayo del mismo año, Parenzo fue asesinado. Sin duda, la cuestión pontificia se vio reforzada por este teórico martirio del rector -se convirtió en patrono de Orvieto- pero, a su vez, su asesinato denotaba la falta de autoridad de la institución eclesiástica, el fortalecimiento de la herejía y la evidente insuficiencia de las medidas recogidas en la bula $A d$ abolendam ${ }^{38}$.

\section{LA CARTA AL OBISPO DE SiRACUSA}

Para afrontar esta insuficiencia, la cancillería pontificia redactó la decretal Vergentis in senium, promulgada el 25 de marzo de 1199 dirigida a los gobernantes de Viterbo ${ }^{39}$, y precedida de una carta que, en enero de 1198, Inocencio III había enviado al obispo de Siracusa, una vez que tuvo conocimiento de la propagación de la herejía en la diócesis siciliana ${ }^{40}$. Incluso en el incipit, así como en su contenido y en su distribución en el texto, la misiva enviada a Siracusa constituye

excresceret numerus, quod contra Catholicos publice praedicabant, dicentes, quod si belli contra illos immineret necessitas, eis extra Civitatem cogerent miserabiliter exulare. Iam enim mente conceperat conspirante, ut si Catholicos non posent ad suae iniquitatis perfidiam inclinare, ipsorum ablatis divitiis, et personie eiectis, et mortis supplicio subiugantis, Civitatem ipsam, propter sui munitionem inexpugnabilem, ex omnibus mundi partibus convenientium haereticorum domicilio deputarent, ad Catholicam ecclesiam impugnandam". El autor de la Passio señala que el número de herejes en Orvieto era tal que podían permitirse amenazar de guerra a los católicos. Quien no se hubiera convertido, según las amenazas de los predicadores herejes, habría sufrido la confiscación de sus bienes; algunos católicos habrían sido exiliados, otros asesinados. La Iglesia herética se habría apropiado de Orvieto, una ciudad inexpugnable, que habría dado asilo a todos los herejes del mundo, que, reunidos todos en Orvieto, habrían ejercido desde allí su lucha contra la Iglesia católica.

${ }^{36}$ Ibíd., p. 32.

${ }^{37}$ Duarte Rust, Leandro, Bulas Inquisitoriais: Ad Abolendam (1184) e Vergentis in senium (1199), en Revista de Historia, 166 (Sao Paulo, 2012), p. 144.

${ }^{38} \mathrm{La}$ inestabilidad del poder imperial también había jugado a favor de la causa herética: la represión de la herejía llevada a cabo por las autoridades eclesiásticas no contaba con el apoyo de la autoridad imperial, debilitada por la lucha de sucesión que se había iniciado con la muerte de Enrique VI, y que duraba ya un par de años. Ibíd.

${ }^{39}$ Toda la bula está marcada por una pastoral eclesiástica característica del círculo formado en París, que incluía a Inocencio III y a los cardenales Robert De Courson y Stephen Ngorima. Ibíd., p. 147.

${ }^{40}$ InNocentius III, Ep. 509 Siracusano Episcopo, en PL., 214, coll. 471-472. 
el prototipo sobre el que, pocos meses después, la cancillería pontificia redactó Vergentis in senium.

Precisamente porque el texto de la carta fue transpuesto en la decretal de marzo del mismo año, omitiremos por ahora su análisis, deteniéndonos brevemente en su parte dispositiva.

En ella, Inocencio III ordena al obispo de Siracusa que: “[...] tamquam fidei Christianae zelator assurgas; et si apud eos monitis obtinere non poteris ut redeant ad Ecclesiae unitatem, ipsos, fautores, defensores, et receptatores eorum [...] per totam diocesim in quam fuerint, imo etiam per totam provinciam, singulis diebus Dominici et festivis excomunicatos publice nuntiari facias e bona eorum a principibus pubblicari" ${ }^{41}$.

El obispo siciliano fue ratificado en el cargo de responsable principal de la lucha contra la herejía en su propia diócesis. Este, habiendo invitado a los herejes, mediante la admonición a volver a la comunión eclesiástica, recibía la orden de indicar públicamente, cada domingo y en los días festivos, aquellos que perseveraban en el error, junto con sus protectores, defensores y todos los que les daban asilo, proclamando su excomunión, ordenando que los príncipes les confiscaran sus bienes. A la pena canónica, por lo tanto, el pontífice añadía la pena civil, la confiscación de los bienes por parte de las autoridades civiles.

Una intervención similar conjunta de la autoridad eclesiástica y de la civil era, al tiempo, indispensable a los ojos del pontífice también en el caso de los sarracenos, aún presentes en Sicilia en un número considerable, a pesar de la derrota del Emirato en 1017, obra de la invasión normanda. Para aquellos que, tras haber recibido el bautismo en la Iglesia católica, hubieran continuado participando en los ritos de la religión musulmana o que, habiendo abandonado la fe cristiana, hubieran vuelto a la musulmana, el pontífice establecía que: "frequenti ac diligenti exhortatione praemissa et per te ipsum, quacunque poterit districtione compellas et compelli facias per principes saeculares" ${ }^{42}$.

Sin perjuicio, como de costumbre, de la invitación a volver a la Iglesia de Cristo, el obispo recibía la obligación de forzar a los sarracenos con cualquier medida (quacunque districtione) a convertirse y de asegurarse de que fueran forzados por la intervención de los príncipes seculares.

Como en Ad abolendam, la lucha fructífera contra la herejía debía pasar por la intervención del poder eclesiástico y del civil; del mismo modo, en la carta al obispo de Siracusa ambas espadas debían ser utilizadas también de forma sinérgica. Sin embargo, cambia radicalmente la forma de abordar la cuestión por parte del nuevo pontífice. Con respecto a la bula de Lucio III, que ponía al mismo nivel el poder que emana del regnum y el que emana del sacerdotium, esperando su colaboración (que, por desgracia, no se había producido de la forma que esperaba el pontífice), suenan totalmente nuevas las palabras de Inocencio III, que parece gobernar el siglo al igual que la Iglesia, asumiendo una relación de v a s 11 a j e o dependencia del poder civil con respecto al espiritual, hasta el punto de implicar de forma perentoria a los príncipes sicilianos a través de la intermediación del

\footnotetext{
${ }^{41}$ Ibíd, col. 471.

${ }^{42}$ Ibíd, col. 472.
} 
obispo. En esencia, se pasa de la invitación a la colaboración, deseada por Lucio III y por el mismo Federico Barbarroja -que apoya libremente la causa ortodoxa y colabora con ella activamente, como se desprende del texto de la Ad reprimendam-, a la obligación dirigida al brazo secular, a través del obispo, de ponerse a disposición en esa batalla que ahora adoptaba los tonos de una cruzada para erradicar la plaga herética.

La carta enviada por Inocencio III al obispo de Siracusa (enero 1198), la promulgación de la decretal Vergentis in senium (marzo 1198), junto con la asignación a Pietro Parenzo del cargo de rector de Orvieto (febrero 1199), representan tres etapas de una única reacción del pontífice a la difusión de la herejía en la península italiana, la primera de su pontificado. Estos tres momentos deben ser considerados en su unidad de intenciones, por lo que la comprensión de las razones que subyacen a la estricta decretal pontificia de marzo de 1198 no puede prescindir del análisis de las órdenes enviadas al pastor de Siracusa y de las decisiones políticas que afectaron a Orvieto.

En este tríptico, la lucha contra la herejía constituye indudablemente el objetivo primordial y urgente del pontífice, perseguido -y este es el rasgo dominante del pontificado de Inocencio III- en el contexto de un proyecto más amplio, que pretende dar una aplicación concreta a las teorías hierocráticas que el pontífice había aprendido en la escuela de canonistas de Bolonia y que veían en la Santa Sede la depositaria de todos los poderes espirituales y temporales de todo el mundo, y el centro desde el cual irradiaban todos los poderes eclesiásticos y espirituales que se podían ejercer legítimamente en todo el orbe católico. La oposición definitiva al catarismo, por lo tanto, representó también una ocasión para manifestar a los obispos, a los príncipes y a todo el pueblo de fieles que la titularidad de la plenitudo potestatis, de la plenitud del poder, o del poder en su plenitud, estaba permanentemente encomendada al sucesor de Pedro. En el caso de Orvieto, la aplicación del plan de reforma del Patrimonio de Pedro, que preveía el restablecimiento de la hegemonía feudal de la Santa Sede sobre el centro de Italia y el ejercicio de la influencia pontificia en la administración municipal de la Comuna, estuvo inseparablemente vinculada a la represión de la herejía. A pesar del fracaso del proyecto del pontífice, que concluyó trágicamente con la muerte de Pietro Parenzo, podemos imaginar el caso de Orvieto como el primer intento de aplicación de un programa del joven pontífice, esbozado en la carta al obispo de Siracusa y definido claramente (e impuesto por vía reglamentaria), en la decretal Vergentis in senium ${ }^{43}$.

\section{La Decretal VERGENTIS IN SENIUM}

Pasemos, pues, al texto de la decretal del 25 de marzo de 1198. La primera parte de la medida pontificia adopta los tonos de una homilía: "Vergentis in senium saeculi corruptelam non solum sapiunt elementa corrupta, sed etiam dignississima crea-

\footnotetext{
${ }^{43}$ Pennington, Kenneth, Pro Peccatis Patrum Puniri: A Moral and Legal Problem of the Inquisition, en Church History, 47/2 (1978), pp. 137-154.
} 
turam ad imaginem et similitudinem condita Creatoris, praelata privilegio dignitatis volucribus coeli et bestiis universae terrae testatur, nec tantum eo quasi deficiente iam deficit, sed et inficit et inficitur scabra rubigine vetustatis" 44

Con un tono más bien pesimista, el pontífice observa el envejecimiento del siglo que llega a su fin, comparándolo con la imparable decadencia de la especie humana, que, rechazando la dignidad que por voluntad divina le había sido conferida, se rebela contra el privilegio divino de criatura especial llamada a gobernar la creación, limitándose a corromperse a sí misma y a todo lo que le fue confiado: el hombre no deja de estar infectado y de infectar con la sucia herrumbre de la vejez ${ }^{45}$.

La criatura dignissima, hecha a imagen de Dios, peccat ad extremum, hasta la muerte y encuentra su disolución llevando a la disolución de la creación. Ocupada con cuestiones mundanas, se olvida del precio pagado por su redención al final de los tiempos y se ata a las cadenas de su pecado: cae en la trampa que ella misma se ha preparado ${ }^{46}$.

El pontífice pinta una escena con colores oscuros. El hombre malvado siembra la semilla del mal en los campos del Señor y deja que crezca la cizaña, mientras que el trigo se disuelve en la paja y los parásitos atacan a las flores y los zorros a los frutos de la viña del Señor: "Ecce, etenim, inimico homine messi dominicae superseminante semen iniquum, segetes in zizania pullulant, vel potius pulluuntur, triticum acrescit et evanescit in paleam, in flore tinea et vulpes in fructu demoliri vineam Domini moliuntur" ${ }^{4}$.

La estirpe humana, que no logra conservar el estado de gracia que le confiere la nueva alianza con el Señor, está fuera de control: la noche se comporta como maestra de la noche, el ciego ofrece guía al ciego y las herejías rebosan por todas partes, de forma que, mientras que el hereje se construye su doctrina, haciendo prosélitos, priva al heredero de la herencia divina ${ }^{48}$.

El hereje mismo, continúa el pontífice, es mentiroso, como el posadero que agua el vino, ofreciendo el veneno del dragón en un cáliz de oro en un mundo que se asemeja a la Babilonia veterotestamentaria. Los herejes desprecian la fe y niegan su virtud ${ }^{49}$.

En realidad, el pesimismo del pontífice no debe sorprender: el contemptus mundi era un topos clásico de Lotario dei Segni desde que, joven noble constituido cardenal con solo treinta años por Clemente III, fue apartado por su sucesor por

${ }^{44}$ X 5.7. 10 .

${ }^{45}$ Duarte Rust, Leandro, Bulas Inquisitorias, cit. (n. 37), p. 140.

46 "Peccat enim ad extremum homo miserrimus, et, qui non potuit in sui et mundi creatione in paradiso persistere, circa sui et orbis dissolutionem degenerat, et pretii suae redemptionis circa fine saeculorum oblitus, dum variis ac vanis quaestionum se nexibus ingerit, se ipsum laqueis suae fraudis innectit, et incidit in foveam, quam paravit”, X 5. 7. 10.

${ }^{47}$ Ibíd.

48 "[...] dum nox nocti scientiam indicat, dum caecus praebet caeco ducatum, dum haereses pullulant, et quem divinae reddit hereditatis expertem, suae constituit haereticus haeresis et damnationis haeredem", ibíd.

49 "Hi sunt caupones, qui acquam vino commiscent, et vinus draconis in aureo calice Babylonis propinant, habentes, secundum Apostolum, speciem pietatis, virtutem autem eius penitus abnegantes", ibíd. 
razones de conveniencia política. La profunda reflexión sobre sí mismo y sobre la situación sociopolítica que le rodeaba acompañó la redacción de una serie de opúsculos teológico-ascéticos (1191-1198), entre ellos el célebre De contemptu mundi sive de miseria conditionis humanae ${ }^{50}$.

Este pesimismo, claramente, no puede reducirse a una cuestión estilística o a un ejercicio de homilética. Ante la mirada del joven pontífice hubo una serie de enfrentamientos en los dos ámbitos que componían su existencia: con los soberanos con respecto al temporal, con los herejes en el espiritual. En la misma decretal, el pontífice constata con dolor los fracasos de la política anti-herética de sus predecesores: "licet autem contra vulpes huiusmodi parvulas (species quidem habentes diversas, sed caudas ad invicem colligatas, quia de vanitate conveniunt in id ipsum) diversa praedecessorum nostrorum temporibus emanaverint instituta: nondum tamen usque adeo pestis potuit mortificari mortifera, quin, sicut cancer, amlius serperet in occulto, et iam in aperto suae virus iniquitatis effundat, dum palliata specie religionis et multos decipit simplices, et quosdam seducit astutos, factus magister erroris, qui non fuerat discipulus veritatis" ${ }^{51}$.

La situación esbozada por Inocencio es preocupante: sus antecesores han intentado frenar el asalto a la viña del Señor llevado a cabo por pequeños pero numerosos zorros, (pertenecientes a especies diferentes) pero todas unidas por la cola, porque convergen todas en cuanto a su falsedad. Sin embargo, los esfuerzos realizados no han tenido el efecto deseado: la mortífera peste de la herejía, como un cáncer, en tiempos más remotos había serpenteado a escondidas, mientras que en la época de Inocencio ahora difundía abiertamente su veneno contaminante. Ninguna medida había sido capaz de erradicarla por completo. Los fracasos de las intervenciones pontificias habían permitido que la herejía se propagara no solo entre los simples, entre los miembros ignorantes del pueblo, fáciles de engañar, sino también entre los más astutos, por lo que se convirtió en maestro del error quien nunca antes había sido discípulo de la verdad (“factus magister erroris, qui non fuerat discipolus veritatis").

El pontífice, por lo tanto, decide intervenir duramente, para no dar la im-

${ }^{50}$ InNOCENTIUS III, De contemptu mundi sive de miseria conditionis humanae, en PL., 217, pp. 703-737; ARCHTERFELDT, Johannes (ed.), Innocentii III contemptus mundi (Bonn, 1855). Se trata de un análisis lúcido y detallado sobre la condición humana, que pone de relieve su mezquindad y que impide al hombre escapar de la miseria en la que se encuentra de forma natural e inexorable. Constituye un ejemplo la reflexión sobre la felicidad: "Quis unquam vel unicum diem totum duxit in sua delectatione iucundum, quem in aliqua parte diei reatus conscientiae, vel impetus irae, vel motus concupiscientiae non turbaverit? Quem livor invidiae vel ardor avaritiae, vel tumor superbiae non vexaverit? Quem aliqua iactura, vel offensa, vel passio non commoverit? Quem denique visus vel auditus vel actus aliquis non offenderit?" (c. XXII, De brevi laetitia hominis, p. 713). Con una prosa muy elegante, Lotario dei Segni reflexiona sobre la imposibilidad de vivir al menos un día entero plenamente feliz: ¿̧hay acaso alguien que pueda afirmar haber vivido un día entero felizmente, sin haberse sentido molesto en ningún momento por un remordimiento, por un arrebato de ira, por el impulso de un deseo? ¿Que no haya sido molestado por el livor de la envidia o por el ardor de la avaricia, o por el tumor de la soberbia? ¿Que no haya sido sacudido por alguna desventura, ofensa o pasión? ¿Que, finalmente, no se haya sentido ofendido por un rostro, una frase o un gesto?

${ }^{51}$ X 5.7. 10 . 
presión de querer abstenerse de defender a la Iglesia, precisamente él quien, por mandato divino, es su líder y tiene el deber de protegerla. Inocencio no pretende eludir la tarea de "atrapar a los zorros y alejar a los lobos de las ovejas", evitando parecer abandonista o impotente, como un perro mudo, incapaz de ladrar, mientras los herejes continúan devastando la Iglesia de Cristo ${ }^{52}$ : "ne autem nos, qui licet circa horam undecimam inter operarios, immo verius super operarios vineae Domini Sabaoth sumus a paterfamilias evangelico deputati, et quibus ex officio pastorali sunt oves Christi commissae, nec capere vulpes demolientes vineam Domini, nec arcere lupos ab ovibus videamur, et ob hoc merito vocari possimus canes muti non valentes latrare" 53 .

Esta larga premisa va seguida de la parte dispositiva de la decretal. Tratando de dar un nuevo impulso a la lucha contra la herejía, el papa reafirma las medidas ya adoptadas en Ad abolendam y se erige como el aplicador directo de la disciplina dictada por Lucio III unos años antes ${ }^{54}$. No modifica, por ejemplo, el tratamiento de aquellos a los que la Iglesia de Roma, los obispos diocesanos o incluso el clero local, en caso de sede vacante, han juzgado como herejes: estos, de hecho, son castigados con la excomunión eterna (perpetui anathematis innodamus) decretaba por Lucio III unos años antes ${ }^{55}$.

Sin embargo, dado que la situación había empeorado aún más, el pontífice considera conveniente adoptar medidas más estrictas contra los defensores de los herejes, sus instigadores, sus protectores y aquellos que creen en las doctrinas falsas, para que, aquellos que no pueden volver por sí solos al camino de la rectitud, al verse evitados por todos, sean inducidos a desear nuevamente la comunión ${ }^{56}$. Por lo tanto, de común acuerdo con los cardenales y los arzobispos y obispos presentes en Roma, Inocencio prohíbe más severamente acoger o defender a los herejes, protegerlos o creerles en cualquier cosa, decretando que, en caso de infracción, en caso de que el culpable no tenga en cuenta ni la primera ni la segunda admonición, y persista en la conducta ilegítima, ipso iure será hecho infame, y no podrá ser admitido a los oficios públicos o a los consejos ciudadanos, ni a las elecciones para la provisión de estos cargos, y no se le permitirá testificar ${ }^{57}$. Además, el culpable

${ }^{52}$ Cfr. Kendall, Keith, "Mute dogs, unable to Bark": Innocent III's call to combat heresy, en Medieval Church Law and the Origins of the Western Legal Tradition: A Tribute to Kenneth Pennington (Washington, 2006), pp. 170-178.

${ }^{53} \mathrm{X}$ 5.7. 10.

${ }^{54}$ Bolton, Brenda, Tradition and Temerity: Papal attitudes to Deviants, 1159-1216, en BAKer, Derek (ed.), Schism, Heresy and Religious Protest (Cambridge, 1972), pp. 79-92.

${ }^{55}$ Brundage, James, The Hierarchy of Violence in Twelfth-and Thirteenth-Century Canonists, en The International History Review, 17/4 (1995), pp. 674-676.

56 "[...] contra defensores, receptatores, fautores et credentes haereticorum aliquid severius duximus statuendum, $u t$, qui per se ad viam rectitudinis revocari non possunt [...] cum se videnint ab omnibus evitari, reconciliare desiderent omnium unitati", X 5. 7. 10.

57 "De communi ergo fratrum nostrorum consilio, assensu quoque archiepiscoporum et episcoporum apud sedem apostolicam existentium, districtius inhibemus ne quis haereticos receptare quomodolibet vel defensare, aut ipsis favere vel credere quoquo modo praesumat, presenti decreto firmiter statuentes, ut, si quis aliquid horum facere praesumpserit, nisi primo secundove commonitus a sua super hoc curaverit praesumptione cessare, ipso iure sit factus infamis, nec ad publica officia vel consilia civitatum, nec ad eligendos aliquos ad huiusmodi, nec ad testimonium admittatur", ibíd. 
se vuelve incapaz de disponer de sus propios bienes mediante testamento, y no puede acceder a la sucesión en la herencia ${ }^{58}$.

Nadie puede ser llamado a juicio para responder por un negocio frente a quien adopta, protege, defiende o cree a los herejes: pierden su legitimación activa en el juicio. Pero hay más: quien adopta las conductas peligrosas que favorecen la difusión de la herejía no puede desempeñar ningún cargo estable en los tribunales, es decir, su contacto con la mentira le haría inhábil para buscar la verdad para aplicar la justicia. Por lo tanto, si el culpable que favorece al hereje es un juez, su sentencia es nula, y en el futuro no se le podrá asignar la decisión de ninguna otra causa. Si, por el contrario, es abogado, el culpable pierde por completo la facultad de ejercer su defensa. Por último, si es notario, los actos que él haya realizado no tienen valor jurídico, sino que son condenados junto con su autor ${ }^{59}$.

Si las conductas sancionadas por el decreto son adoptadas por un clérigo, el pontífice establece que sea destituido de cualquier cargo y beneficio, para que, en los que tienen más culpa, más grave se ejerza la venganza ${ }^{60}$.

El pontífice, retomando la categoría romanística de la i n f a $\mathrm{m}$ i a , relacionada con la consumación de los delitos más graves, demuestra ser un gran conocedor del derecho civil ${ }^{61}$. De la misma forma, el alejamiento de los cargos públicos, la pérdida de las dignidades imperiales ${ }^{62}$ y la prohibición de ejercer la profesión de abogado $^{63}$ ya estaban establecidas por el derecho imperial justinianeo contra los herejes. También lo estaban la pérdida de la facultad de hacer testamento o de adquirir el status de heredero ${ }^{64}$ y las limitaciones relacionadas con el derecho procesal, desde la legitimación activa en la causa a la capacidad de testificar ${ }^{65}$. Inocencio toma prestada la disciplina antiherética imperial, sin aplicarla, no obstante, a los herejes, sino a aquellos que simplemente colaboran con ellos como

58 "Sit etiam intestabilis, nec ad hereditatis successionem accedat", ibíd.

59 "Nullus praeterea ipsi cogatur super quocumque negotio respondere. Quod si forte iudex exstiterit, eius sententia nullam obtineat firmitatem, nec causae aliquae ad eius audientiam perferantur. Si fuerit advocatus, eius patrocinium nullatenus admittatur. Si tabellio, instrumenta confecta per ipsum nullius sit penitus momenti, sed cum auctore damnato damnentur", ibíd.

60 "Si vero clericus fuerit, ab omni officio et beneficio deponatur, ut, in quo maior est culpa, gravior excerceatur vindicta”, ibíd.

${ }^{61}$ De hecho, ya el Codex Theodosianus prescribía la infamia contra los culpables de herejía: "[...] ut infamibus atque probrosis a coetu hominum segregatis" (C.Th. 16, 5, 3); “[...] sub perpetua inustae infamiae nota [...]" (C.Th. 16, 5, 7 pr.); "Donatistas atque haereticos [...] perpetua inustos infamia a coetibus honestis et a conventu publico segregandos" (C.Th. 16, 5, 54 pr).

62 "Archigerontes et dioecetae ergasiotanorum non nisi christiani dirigantur" (C.I. 1, 4, 5); C.I. 1, 5, 12, 6-7; C.I. 1, 5, 18, 4-5; “[...] nec quodlibet in publicia curis participium haberent [...]" (Nov. 109 pr.).

${ }_{63}$ "Nemo vel in foro magnitudinis tuae vel in provinciali iudicio vel apud quemquam iudicem accedat ad togatorum consortium, nisi sacrosanctis catholicae religionis fuerit imbutus mysteriis" (C.I. 1, 4, 15).

${ }^{64} \mathrm{Cfr}$. las limitaciones al derecho de sucesión impuestas a los herejes por el derecho romano en C.Th. 16, 5, 7, 2; C.Th. 16, 5, 9 pr.; C.Th. 16, 5, 17; C.Th. 16, 5, 25, 1; C.Th. 16, 5, 40, 3 = C.I. 1, 5, 4, 2; C.Th. 16, 5, 40, 5 = C.I. 1, 5, 4, 5; C.Th. 16, 5, 49; C.Th. 16, 5, 54 pr.; C.Th. 16, 5, 58, 4; C.Th. 16, 5, 65, 3; C.Th. 16, 6, 4, 3; C.I. 1, 6, 3, 1; C.I. 1, 7, 3 pr.; Nov. 115, 3, 14.

${ }^{65}$ Cfr. C.I. $1,5,21,1$. 
protectores o defensores o a aquellos que, de alguna forma, osen creer en ellos. La mayor severidad de la disciplina penal imperial encuentra aquí aplicación para sancionar las conductas s o c i a l m e n te peligros as. La mayor severidad de la disciplina, anunciada por el pontífice en el preámbulo, emerge ahora claramente en la parte dispositiva.

Además de las sanciones prescritas hasta ahora, y que recuerdan a la justicia civil más que a la eclesiástica, el legislador añade la excomunión: "si quis autem tales, postquam ab ecclesia fuerint denotati contempserit evitare, anathematis se noverit sententiam incurrisse" ${ }^{66}$.

La última parte de la parte dispositiva hace referencia a la confiscación de los bienes, que se convierte para Inocencio en una ocasión para afirmar la titularidad de la autoridad suprema, de la plenitud de poderes, con respecto al romano pontífice. Reforzando la posición ya adoptada en la misiva al obispo de Siracusa, se dirige a los soberanos como si fueran titulares de una potestad delegada, de regencia administrativa, que aquel que ha sido constituido cúspide de todo poder por la Divina Providencia, el vicario de Cristo y obispo de Roma, delega por razones de conveniencia, debiendo dar prioridad al ejercicio de las funciones espirituales.

La autoridad en su totalidad, es decir, todo el poder que Dios quiso conceder sobre el mundo -dividido entre el espiritual y el temporal-, el pontífice lo ejerce en parte directamente, en parte de forma delegada, como cuando se sirve de los soberanos para la administración de los reinos: a ellos se les delega no ya la auctoritas, el mandato, sino una potestas mucho más limitada, la potestad administrativa.

Esta es la concepción teocrática del poder en auge en la Baja Edad Media. Tiene sus raíces en la necesidad de reductio ad unum que animaba la reflexión de los doctores del derecho de la universidad de Bolonia, orientados a poner orden en la constelación de ordenamientos grandes y pequeños que formaban parte del gran imperio, el ordenamiento universal que los contenía a todos ${ }^{67}$.

Los canonistas estudiaban el ordenamiento universal, por excelencia, el de la Iglesia, que, a diferencia de lo que esperaba el nostálgico ideal imperialista, encontraba eficazmente su aplicación en todo el orbe católico y potencialmente en todo el mundo. Habían construido cuidadosamente una teoría unitaria de fuentes del derecho para dar un orden armónico a la pluralidad de fuentes universales y particulares que se hacinaban dentro y fuera del derecho canónico. El sistema de delegaciones de la potestas basado en el vínculo de fidelidad se refería explícitamente al sistema de vasallaje, que había permitido el gobierno del imperio desde la Alta Edad Media.

Lotario dei Segni, que había estudiado este $s$ is t e m a en la Universidad de Bolonia, tuvo el gran mérito de ponerlo en práctica con determinación, demostrando cómo una teoría de las fuentes, elaborada por la comunidad científica y asimilada por los máximos representantes del gobierno, puede incidir significativamente en los equilibrios políticos, revirtiendo de hecho, como nunca antes había sucedido, las relaciones entre el papado y el imperio ${ }^{68}$. Basándose en las

\footnotetext{
${ }^{66} \mathrm{X}$ 5.7. 10.

${ }^{67}$ Cavanna, Adriano, Storia del diritto moderno in Europa (Milano, 1982), p. 50.

${ }^{68}$ MorÁn Gloria, La canonistica medieval y su contribución al desarrollo del pensamiento
} 
teorías doctrinales que aprendió cuando era estudiante de derecho, ejerció durante todo su pontificado sabiendo que era titular de la autoridad suprema que Dios le había encomendado e incluso de una potestad directa de la Iglesia en las cuestiones temporales (potestas directa Ecclesiae in temporalibus), que debía ejercer de manera subsidiaria, en caso de ausencia o negligencia del titular de la potestas.

En el mismo año que Vergentis in senium, 1198, en la carta Sicut universitatis conditor, Inocencio ilustró magistralmente la concepción teocrática del poder recurriendo a la célebre metáfora de la luna y el sol: "Sicut universitatis conditor Deus duo magna luminaria in firmamento coeli constituit, luminare maius, ut praeesset diei, et luminare minus, ut nocti praeesset; sic ad firmamentum universalis Ecclesiae, quae coeli nomine nuncupatur, duas magnas instituit dignitates: maiorem, quae quasi diebus animabus praeesset et minorem, quae quasi noctibus praeesset corporibus: quae sunt pontificalis auctoritas et regalis potestas. Porro sicut luna lumen suum a sole sortitur, quae re vera minor est illo quantitate simul et qualitate, situ pariter et effectu: sic regalis potestas ab auctoritate pontificalis suae sortitur dignitatis splendorem; cuius conspectui quanto magis inhaeret, tanto maiori lumine decoratur; et quo plus ab eius elongatur aspectu, eo plus proficit in splendore. Utraque vero potestas sive primatus sedem in Italiam meruit obtinere, quae dispositione divina super universas provincias obtinuit principatum [...]"' . He aquí su traducción: "Del mismo modo que Dios, creador del universo, ha creado dos grandes luces en el firmamento del cielo, la más grande para presidir el día y la más pequeña para presidir la noche, también ha establecido, en el firmamento de la Iglesia universal, que sería el cielo, dos grandes dignidades: la más grande para presidir (por así decirlo) los días, es decir, las almas, y la más pequeña para presidir las noches, es decir, los cuerpos. Se trata de la autoridad pontificia y del poder regio. De este modo, al igual que la luna, que recibe su luz del sol y por esa razón es inferior a él en cantidad y calidad, tamaño y efectos, el poder regio obtiene de la autoridad del papa el esplendor de su dignidad y cuanto más está en contacto con ella, mayor es la luz que la adorna, y cuanto más lejos está de ella, menor es el esplendor que obtiene. Ambos poderes han tenido la sede de su primacía en Italia, un país que obtuvo, por lo tanto, la primacía sobre cualquier otro por voluntad divina”.

Esta teorización articulada del gobierno unitario en el mundo en manos del vicario de Cristo encuentra espacio en pocas líneas de la Vergentis in senium: "In terris vero temporali, nostrae iurisdictioni subiectis, bona haereticorum statuimus publicari, et in aliis idem praecipimus fieri per potestates et principes saeculares, quod ad id exsequendum, si forte negligentes exstiterint, per censuram ecclesiasticam appellatione remota compelli volumus et mandamus"70.

En las tierras sujetas al poder temporal del pontífice, es decir, en las que el poder temporal no había sido delegado a los príncipes y a otros soberanos, Inocencio establecía que fueran confiscados los bienes de los herejes. Lo mismo p r e s c r i bí a ordenaba (praecipimus) que establecieran también los príncipes seculares en el ejercicio de sus potestades (per potestates). Si ellos, al cumplir este

constitucional contemporáneo, en Ius Ecclesiae, 24 (2012), pp. 363 y ss.

${ }^{69}$ INNOCENTIUS III, Epistola n. 401 (pontificatus annus I, Christi 1198), en PL., 214, col. 377.

${ }^{70} \mathrm{X}$ 5. 7. 10 . 
mandato, parecían negligentes, el pontífice ordenaba que fueran obligados por medio de la censura eclesiástica, sin posibilidad de apelación. De este modo, el mandato del titular de la auctoritas, llegaba a todos los soberanos, dado el valor jurídico universal que, desde la época imperial, se atribuía al dispositivo de los rescriptos y de las decretales pontificias.

Tan extendida estaba la difusión de la herejía en Europa, que la colaboración del poder civil era ahora indispensable, de modo que al menos la pena temporal habría reprimido lo que la pena espiritual, por sí sola, no era capaz de corregir ${ }^{71}$.

Por lo tanto, el pontífice impone a los príncipes que apliquen estrictamente la sanción de la confiscación, excepto la posibilidad de indultar al culpable arrepentido y convertido ${ }^{72}$. Si, cuando se viola la majestad temporal, los príncipes aplican estrictamente la pena capital y confiscan los bienes incluso cuando tienen hijos ortodoxos (por razones de misericordia a estos últimos se les perdona la vida $)^{73}$, con mayor razón, cuando se viola la majestad eterna, que es mucho más importante, la pena canónica que rompe los lazos con la Iglesia y con su Líder, y la confiscación de los bienes deben aplicarse con mayor rigor ${ }^{74}$.

Como gran jurista y experto conocedor del derecho romano, Inocencio III también tomó prestada del derecho de los césares la categoría de c r i m e n d e les a majestad, en la que incluyó el odioso delito de herejía ${ }^{75}$. La asimilación de la herejía al delito de lesa majestad no constituye una novedad en el panorama jurídico civil. Como hemos mencionado, ya en una constitución del 22 de febrero de 407, incluida en el Código Teodosiano y después en el Codex de Justiniano (C.Th. 16, 5, 40, 5 = C.I. 1, 5, 4, 4), el tratamiento procesal del culpable de herejía era el mismo ya previsto para los delitos de lesa majestad ${ }^{76}$,

71 "[...] ut temporalis saltem poena corripiat quem spiritualis non corrigit disciplina”, ibíd.

72 "Nec ad eos bona eorum ulterius revertantur, nisi eis, ad cor revertentibus, et abnegantibus haereticorum consortium, misereri aliquis voluit”, ibíd.

${ }^{73}$ El tratamiento de los hijos ortodoxos de padres heréticos en el derecho justinianeo era mucho más clemente: se había dejado intacto el derecho a recibir la herencia que les correspondía, y conservaban el derecho a los alimentos y, más en general, a ser mantenidos por sus padres, independientemente de la fe que estos últimos profesaran. Los hijos heréticos, por otro lado, perdían por completo estos derechos. Cfr., entre otras, C.I. 1, 5, 19, 1; C.I. 1, 5, 19, 3; Nov. $115,3,14$.

74 "Quum enim secundum legitimas sanctiones, reis lesae maiestatis punitis capite, bona confiscentur eorum, filiis suis vita solummodo ex misericordia conservata: quanto magis, qui aberrantes, in fide Domini Dei Filium Iesum Christum offendunt, a capite nostro, quod est Christus, ecclesiastica debent districtione praecidi, et bonis temporalibus spoliari, quum logne sit gravius aeternam quam temporalem laedere maiestatem?”, X 5. 7. 10.

${ }^{75}$ Cf. C. 9, 8, 5, que imponía para el culpable de lesa majestad la pena más severa, es decir, la muerte y la confiscación de sus bienes: "Imperatores Arcadius, Honorius. Quisquis cum militibus vel privatis, barbaris etiam scelestam inierit factionem aut factionis ipsius susceperit sacramenta vel dederit, de nece etiam virorum illustrium qui consiliis et consistorio nostro intersunt, senatorum etiam (nam et ipsi pars corporis nostri sunt), cuiuslibet postremo qui nobis militat cogitarit (eadem enim severitate voluntatem sceleris qua effectum puniri iura voluerunt), ipse quidem utpote maiestatis reus gladio feriatur, bonis eius omnibus fisco nostro addictis" (cf. el texto en KRUEGER, Paul (a cura di), Corpus Iuris Civilis: volumen secundum, Codex (Berlín, 1889), p. 98.

76 "In mortem quoque inquisitio tendit. Nam si in criminibus maiestatis licet memoriam accusare defuncti, non inmerito et hic debet subire iudicium" (C.Th. 16, 5, 40, 5). 
pasando a disposiciones conciliares y manteniéndose en la mens jurídica tanto eclesiástica como civil hasta ser un conceto habitual de la doctrina de la época ${ }^{77}$.

La dureza de las disposiciones era tal que el castigo se extendía a familiares y personas cercanas a ellos. El hecho de que los hijos, aunque ortodoxos, se vieran afectados por la confiscación de los bienes de sus padres, según Inocencio, no debía considerarse un castigo desproporcionado. Las Sagradas Escrituras enseñan que incluso el juicio divino en ocasiones castiga a los hijos (en el plano temporal) por las faltas de sus padres; de la misma forma, las sanciones canónicas contra aquellos que adoptan conductas criminales graves pueden y deben castigar también a la descendencia de los afectados ${ }^{78}$.

Así pues, familiares y quienes colaboraban con los herejes eran culpables del crimen de lesa majestad. Bastaba con adoptar conductas peligrosas, es decir que, de alguna manera pudieran facilitar la propagación de la plaga herética, para ser declarado culpable de haber violado la divina majestad de Jesucristo.

El pontífice, consciente de que es el depositario de todos los poderes, ordena a los príncipes aplicar a gran escala medidas de carácter civil ${ }^{79}$. El uso de medidas civiles para corregir conductas peligrosas para la verdadera fe y, más en general, la conmistión, en las medidas del pontífice, del plano espiritual con el secular será una constante del pontificado inocenciano.

Si la Ad abolendam contó con el respaldo de una asamblea, la decretal de Inocencio no gozaba de tal apoyo, ni del de la máxima autoridad civil, el emperador. Al tratarse de una decretal, está orientada a resolver un problema circunstancial y definido, en este caso la lucha contra la herejía en la comuna de Viterbo. Sin embargo, esta asume una validez universal, hasta el punto de que su contenido será recogido en las colecciones de decretales más importantes de la época, hasta pasar al Corpus Iuris Canonici. En este último, así como en las colecciones anteriores, la Ad abolendam y la Vergentis in senium estaban recogidas una tras otra, puesto que la segunda completaba la primera con un aumento de las penas, siendo ambas bases fundamentales para actuaciones posteriores ${ }^{80}$. Sin embargo, su importancia no nos puede hacer penar que se produce un antes y un después más bien, Inocencio lo que hace es organizar de modo articulado la represión que se estaba llevando hasta el momento, y que alcanzará su cénit al final de su pontificado ${ }^{81}$.

${ }^{77}$ Aparece mencionado, entre otros, en el Concilio de Calcedonia del 451, en los Annales Regni Francorum del 801, en el fragmento de la Constitutio del emperador Enrique III (1052) o los Decretos de Ivo de Chartres (1094) y de Graciano (1140).

78 "Nec huiusmodi severitate censuram orthodoxorum etiam exheredati filiorum quasi cuiusdam miserationis praetextu debet ullatenus impedire, quum in multis casibus etiam secundum divinum iudicium filii pro patribus temporaliter puniatur, et iuxta canonicas sanctiones quandoque feratur ultio non solum in auctores scelerum, sed etiam in progenie damnatorum", X 5. 7. 10.

${ }^{79}$ DuARTE Rust, Leandro, Bulas Inquisitoriais, cit., (n. 37) p. 146.

${ }^{80}$ Todas las características mencionadas de la Vergentis in senium hacen que la historiografía le atribuya una enorme (Cfr. Cardini, Franco, Montesano, Marina, La Lunga Storia dell'Inquisizione: Luci e ombre della “leggenda nera”(Roma, 2007), p. 19; DUARTE RUST, Leandro, Bulas Inquisitoriais, cit. (n. 37), p. 145).

${ }_{81}$ Duarte, ya antes que nosotros, no compartió esta idea de ruptura con lo anterior, separándose de la opinión de Ullman (Cfr. UlLmanN, Walter, The Significance of Innocent III's 
En cualquier caso, si bien la Iglesia de Roma difundió rápidamente la bula de 1198 (en menos de cinco años, el pontífice reforzó la ortodoxia en Languedoc y en los reinos cristianos, desde Aragón hasta Hungría), sin embargo, las normas no se aplicaron homogéneamente. Ya se tenía la normativa, hacía falta ahora, sin duda, un programa estructural que diera una réplica integral a la herejía no sólo en ámbito judicial sino sacramental y formativo. Inocencio, consciente de esa necesidad de dar una respuesta orgánica que sirviera para poder hacer llegar la reforma a todos los niveles, decidió convocar un concilio el Concilio Lateranense IV.

\section{Epílogo}

El Concilio Lateranense IV (1215), finalmente, dio una respuesta sistemática a la lucha contra la herejía, preparando un ejercicio eficiente de los tria munera y, por tanto, una reforma integral de la Iglesia con vistas a cumplir mejor el mandato divino para el que fue instituida. El Concilio Ecuménico fue el acto conclusivo de un largo pontificado, que dejará a los sucesores de Inocencio una Iglesia más consciente de su misión y capaz de dar una respuesta sistemática a la plaga de la herejía, combatiéndola en varios frentes, tantos como funciones ejerce.

El Concilio llevó a cabo una labor de recopilación y armonización de la disciplina antiherética, que se iba sedimentando desde el pontificado de Lucio III. Los textos de las intervenciones normativas anteriores, en concreto de las decretales $A d$ abolendam (1184) y Vergentis in senium (1198), fueron recogidos y reordenados en el can. 3 de haereticis del Concilio.

La disciplina de las inquisitiones (can. 8), por otra parte, es un conjunto de decisiones normativas ya adoptadas por Inocencio III durante su pontificado. Esta madura el proceso de surgimiento de la inquisitio como un modo de proceder que deja un mayor margen de acción al juez, especialmente en la fase introductoria del juicio, sin suprimir las garantías de defensa para la protección del fiel sometido a un proceso, ni sacrificar la búsqueda de la verdad objetiva. En particular, X 5 . 3. 31, sobre el proceso por simonía contra un abad, contiene gran parte del texto que fue mencionado por la cancillería pontificia en el can. 8. Otros aspectos de la inquisitio ya habían sido regulados en X 5.1.9 y X 5.1. 17 y fueron incluidos en la disposición conciliar. De modo que, también en materia de derecho procesal, el Concilio Lateranense IV recoge y completa las novedades en materia de derecho procesal ya surgidas durante el pontificado de Inocencio III, dándoles una organización completa.

Se puede desarrollar un razonamiento similar sobre el decreto conciliar relativo a la formación del clero y de todos los fieles (can. 11), que recoge expresamente las decisiones ya tomadas en el Concilio Lateranense III, a las que añade la disciplina sobre la formación superior en teología.

También madura en los decretos conciliares la reforma de los religiosos, precedida por la intuición inocenciana de acoger en el seno de la Iglesia a las

Decretal Vergentis, en Études d'histoire du droit canonique dédiées à Gabriel Le Bras (Paris, 1965), I, pp. 729-742; DuARTE Rust, Leandro, Bulas Inquisitoriais, cit. n. 37, p. 146). 
órdenes mendicantes, empezando por los hermanos menores que vivían bajo la regla de Francisco de Asís.

En las disposiciones citadas, el problema de la lucha contra la herejía, cuando no se aborda explícitamente, sigue siendo la preocupación subyacente a la intención de reforma de Inocencio III. Una intención constantemente presente a lo largo de la parábola de su pontificado, que comienza, como hemos mencionado, en 1198, año de la promulgación de Vergentis in senium, y concluye en 1216, poco menos de un año después de la conclusión de los trabajos del Concilio Lateranense IV. Este último recoge los frutos, ya maduros, de una experiencia de lucha contra la heterodoxia llevada a cabo en varios frentes, condensada en un articulado ordenado y racional que recoge medidas normativas ya adoptadas y las reúne en una especie de texto único que innova en parte en la disciplina. Al mismo tiempo, el Concilio Lateranense IV es el vehículo de posiciones hierocráticas y papistas de Inocencio III, que se resumen en un legado testamentario de unos setenta cánones, aprobados por la asamblea eclesiástica: éstas, en cierta medida, resumen la intensa actividad legislativa de este Pontífice. Los cánones regulan un gran número de asuntos: desde los dogmas de la fe hasta la disciplina eclesiástica (en continuidad con el espíritu de la reforma gregoriana); desde el derecho sacramental hasta el derecho procesal.

\section{BiBLIOGRAFÍA}

ARCHTERFELDT, Johannes (ed.), Innocentii III contemptus mundi (Bonn, 1855).

BELDA INIESTA, Javier, Civitate evangelii vs evangelium in civitate: el binomio evangeliomundo en la evolución de la vida consagrada medieval, en Commentarium pro Religiosis et Missionariis, 97/1-2 (2015), p. 75-96.

- La respuesta de la Iglesia a la herejía medieval. Aproximación histórico-jurídica (Città del Vaticano, 2014).

BIRD, Jessalynn, Innocent III, Peter the Chanter's Circle, and the Crusade Indulgence: Theory, Implementation, and Aftermath, en SOMmerleChner, Andrea (ed.) Innocenzo III: Urbs et Orbis, Atti del Congresso Internazionale (Roma, 9-15 settembre 1998) (Rome, 2002), I, pp. 503-24.

Bolton, Brenda, Tradition and Temerity: Papal attitudes to Deviants, 1159-1216, en BAKER, Derek (ed.), Schism, Heresy and Religious Protest (Cambridge, 1972), pp. 79-92.

Bourgeors, Nicolas, Les Cisterciens et la croisade de Livonie, en Revue historique, 635/3 (2005), pp. 521-560.

Bravo, Federico, Arte de enseñar, arte de contar. En torno al exemplum medieval, en De La Iglesia Duarte, José Ignacio (coord.), La enseñanza en la edad media: $X$ Semana de Estudios Medievales (Nájera, 1999), pp. 303-328.

BRÉmond, Charles, Le Goff, Jacques, Schmitt Jean Claude, L'Exemplum (Turnhout, 1962).

Brundage, James, The Hierarchy of Violence in Twelfth-and Thirteenth-Century Canonists, en The International History Review, $17 / 4$ (1995), pp. 670-692.

Caelestinus III, Epistola 279 Joachini abbatis, en PL., 206, col. 1183. 
CARDINI Franco, Crociata e religione civica nell'Italia medievale. In "La religion civique à l'époque médiévale et moderne (chrétienté et islam), en Actes du colloque organisé par le Centre de recherche "Histoire sociale et culturelle de l'Occident. XIIe-XVIIIe siècle" de l'Université de Paris X-Nanterre et l'Institut universitaire de France (Nanterre, 21-23 juin 1993) (Rome, 1995) pp. 155-164.

Cardini, Franco, Montesano, Marina, La Lunga Storia dell'Inquisizione: Luci e ombre della "leggenda nera" (Roma, 2007).

Cartari, Stefano (a cura di), Passio S. Petri Parenti Martyris, en Istoria antica latina, e sua traduzione in lingua italiana del Martirio di S. Pietro di Parenzo, (Orvieto, 1662).

Cavanna, Adriano, Storia del diritto moderno in Europa (Milano, 1982).

Clarke, Peter, The Interdict in the Thirteenth Century (Oxford, 2007).

DuARTE Rust, Leandro, Bulas Inquisitoriais: Ad Abolendam (1184) e Vergentis in senium (1199), en Revista de Historia, 166 (Sao Paulo, 2012), pp. 129-161.

Gesta Innocentii Pp. III ab auctore anonymo, sed coetáneo, scripta, n. XVII, en PL., 214, col. 29-30.

Haldén, Peter, Heteronymous Politics beyond Anarchy and Hierarchy: The Multiplication of Forms of Rule 750-1300, en Journal of International Political Theory 13/3 (2017), pp. 266-281.

Heller, Sarah-Grace, Anxiety, Hierarchy, and Appearance in Thirteenth-Century Sumptuary Laws and the Roman de la rose, en French Historical Studies 27/2 (2004), pp. 311-348.

InNOCENTIUS III, De contemptu mundi sive de miseria conditionis humanae, en PL., 217, pp. 703-737;

-Ep. 509 Siracusano Episcopo, en PL., 214, col. 471-472.

- Epistola 94 Aquen. Episcopo et suffraganeis eius, en PL 204, col. 81-83.

—Epistola 97 Guidoni fundatori Hospitalis Sancti Spirtus, en PL., 214, col. 85-86.

-Epistola n. 401 (pontificatus annus I, Christi 1198), en PL., 214, col. 377.

KENDALl, Keith, "Mute dogs, unable to Bark": Innocent III's call to combat heresy, en Medieval Church Law and the Origins of the Western Legal Tradition: A Tribute to Kenneth Pennington (Washington, 2006), pp. 170-178.

KIENZLE, Beverly Mayne, Innocent III's papacy and the crusade years, 1198-1229: Arnaud Amaury, Gui of Vaux-de-Cernay, Foulque of Toulouse, en Heresis 29 (1999), pp. 49-81.

KREHBIEL, Edward, The Interdict: its history and its operations (Washington 1909).

Krueger, Paul (ed.), Corpus Iuris Civilis: volumen secundum, Codex (Berlín, 1889).

LAmbert, Malcolm, The Cathars, Oxford, 1998.

LANSING, Carol, Power \& purity: Cathar Heresy in Medieval Italy (Oxford, 1998).

Loos, Milan, Dualist Heresy in the Middle Ages (Praga 1974).

Maccarrone, Michele, I papi e gli inizi della cristianizzazione della Livonia, en ÉL MISMO, Gli inizi del Cristianesimo in Livonia-Lettonia. Atti del Colloquio internazionale di storia ecclesiastica in occasione dell'8 centenario della chiesa in Livonia (1186-1986) (Città del Vaticano, 1989), pp. 31-80.

-Studi su Innocenzo III (Padua, 1972).

MeschinI, Marco L'evoluzione della normativa antiereticale di Innocenzo III dalla "Vergentis in senium» (1199) al IV concilio lateranense (1215), en Bullettino dell'Istituto Storico Italiano per il Medio Evo, 106/2 (2004), pp. 207-231.

—Validità, novità e carattere della decretale "Vergentis in senium» di Innocenzo III (25 marzo 1199), en Bulletin of the Medieval Canon Law, 25 (2002-2003), pp. 94-113. 
MorÁn Gloria, La canonistica medieval y su contribución al desarrollo del pensamiento constitucional contemporáneo, en Ius ecclesiae 24 (2012), pp. 359-380.

Nichols, Terence, Hierarchy and the Church, en Pro Ecclesia 4/3 (1995), pp. 281-300.

Pennington, Kenneth, Innocent III and the Divine Authority of the Pope, Published in Popes, Canonists, and Texts 1150-1550 (Aldershot, 1993).

-Pro Peccatis Patrum Puniri: A Moral and Legal Problem of the Inquisition, en Church History, 47/2 (1978), pp. 137-154.

Rankin, Travis, Jurisdiction in the Sacrament of Penance: A Canonical - Theological Schema (Leuven, 2011).

Sabatier, Paul, Vita di san Francesco d'Assisi (Milán 1978).

Stevens, Travis Allen, Innocent III et la rhétorique contre l'hérésie, en Brenon, Anne (ed.), 1209-2009: Cathares: Une histoire à pacifier? (Portet-sur-Garonne, 2010), pp. 53-64

Thompson, Augustine, Cities of God: The Religion of the Italian Communes, 1125-1325 (Pennsylvania State University, 2005).

UlLmann, Walter, The Significance of Innocent III's Decretal Vergentis, en Etudes d'histoire du droit canonique dédiées à Gabriel Le Bras (Paris, 1965), I, pp. 729-742.

VICAIre, Marie-Humbert, Vie commune et apostolat missionnaire. Innocent III et la mission de Livonie, en Dominique et ses Prêcheurs, (Fribourg, 1977). 